\title{
Comunicaciones oronasales y oroantrales: Presentación de un caso clínico
}

\author{
RISUEÑO GÓMEZ D * \\ RISUEÑO PENDERIA M ** \\ RUIZ CAÑIZARES $\mathbf{A} * * *$
}

\begin{abstract}
Risueño Gómez D, Risueño Penderia M, Ruiz Cañizares A. Comunicaciones oronasales y oroantrales: Presentación de un caso clínico. Av Periodon Implantol. 2002; 14, 3: 137-141.
\end{abstract}

\begin{abstract}
RESUMEN
Hacemos una revisión de ésta no muy frecuente patología, inducidos por el último caso de origen implantario que se nos ha presentado, observando sus orígenes mas frecuentes, así como los métodos de tratamiento existentes.
\end{abstract}

\section{PALABRAS CLAVE}

Comunicaciones oronasales y oroantrales.

\section{INTRODUCCIÓN}

Estas lesiones, producidas por diversas patologías: Fisuras labio-palatinas mal cicatrizadas son (Figura 1), en su gran mayoría, el origen de las oronasales, con menor incidencia también pueden ser debidas en adultos a infecciones de repetición de los incisivos sus restos radiculares, secuelas traumáticas, extirpación de quistes de la zona (Figura 2), cocainómanos... etc.

Las comunicaciones oroantrales suelen tener su origen más frecuente en extracciones dentarias de los primeros molares (Figura 3), en menos ocasiones por la extracción de los segundos bicúspides, fractura de la pared externa del seno, extirpaciones quirúrgicas.... y últimamente, cómo el caso que presentamos y debido a una perimplantitis no tratada, causa con tendencia a crecer, dado el número cada día más abundante de colocación de implantes en esa zona, mediante técnicas de relleno sinusal.

Se trata de un varón de 60 años piorreico, al que hace 10 años se le colocaron varios implantes y se le realizó tratamiento quirúrgico de su enfermedad parodontal. Por la falta de proceso alveolar a nivel del 16 se practicó apertura del seno con elevación del suelo sinusal, mediante birutas de hueso autólogo e Hidroxiapatita, mezclados con su propia sangre. Ultimamente sufre una perimplantitis (Figura 4) sin sintomatología oral y con la patología de una sinusitis aguda. Por lo cual es eliminado el implante, quedando una fístula oroantral.

Los síntomas mas comunes que presentan estos pacientes, a parte la de su origen traumático, postextracción... etc. son la regurgitación de líquidos y alimentos desde la boca a las cavidades nasales y antral. Sensación de escape de aire por la nariz. En ocasiones, rinolalia abierta.

En un primer momento de la lesión si no existe infección previa de las cavidades, esa es toda la sintomatología. Si se demora el tratamiento de cierre de la fístula, rapidamente, en pocos días, asistiremos a la aparición de nuevos síntomas como salida de pus o aire por el orificio de la fístula, bien espontaneamente $\mathrm{o}$ al realizar la maniobra de Valsalva, así cómo dolor a la presión en fosa canina, dolor a la percusión de los dientes próximos a la lesión. A la exploración nasal encontramos salida de secreción purulenta por debajo del cornete medio. En algunos casos floridos se presenta goteo postnasal faríngeo descendente, al

* Odontólogo práctica privada.

** Cirujano maxilofacial práctica privada.

*** Odontopediatra práctica privada. 


\section{AVANCES}

Volumen 14 - $\mathrm{N}^{\circ} 3$ - Octubre 2002

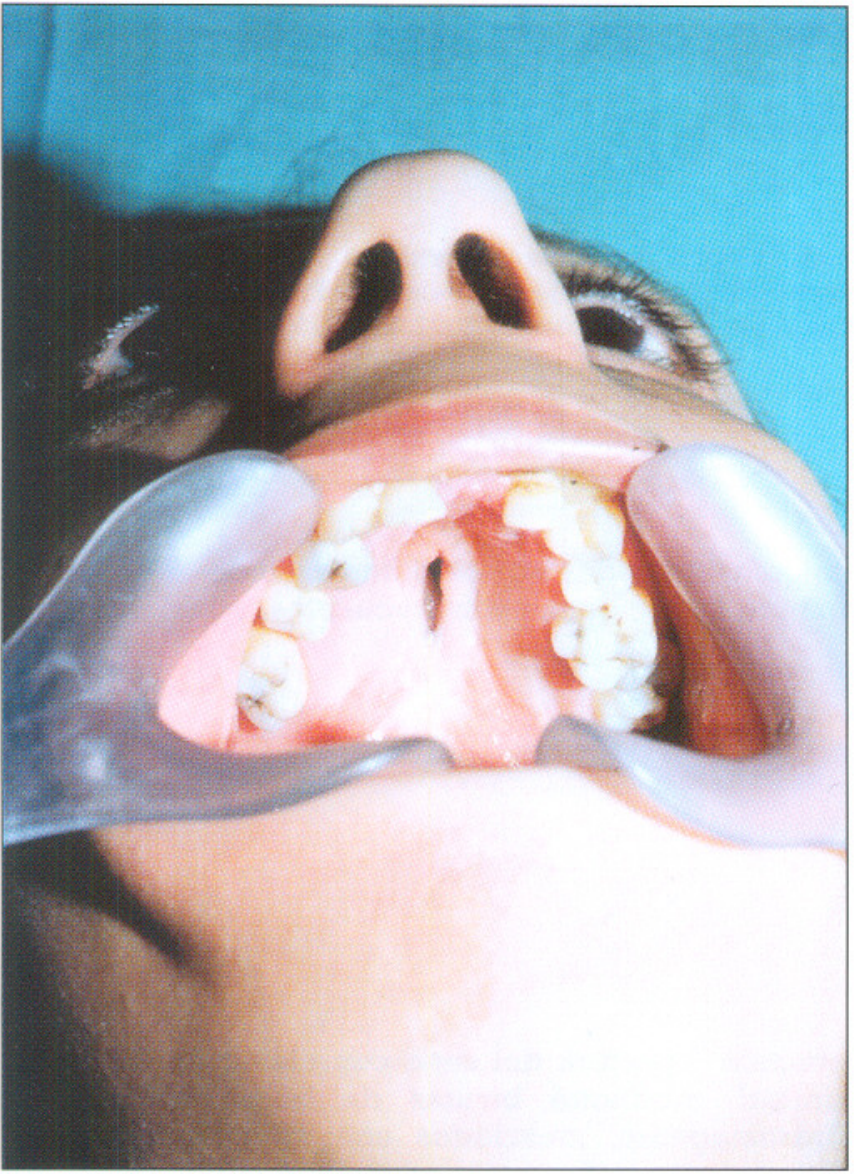

Fig.1

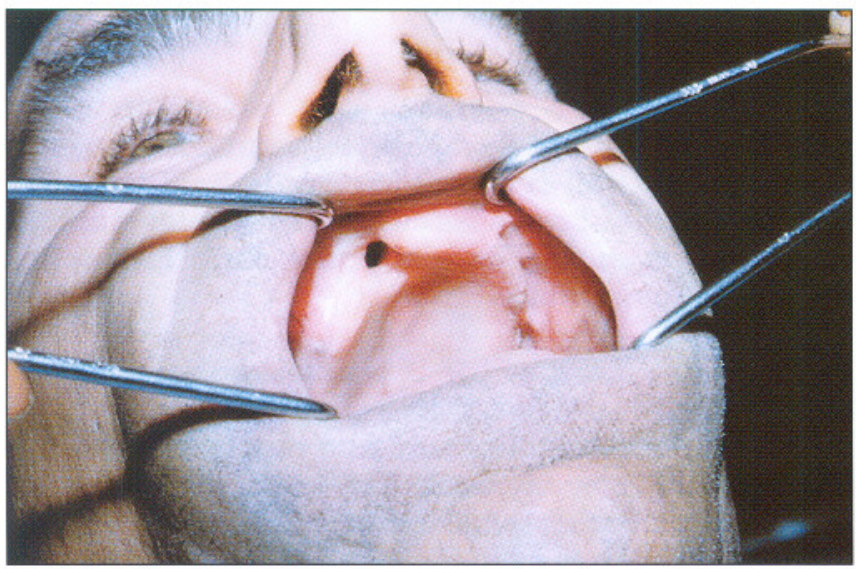

Fig. 2

que se han atribuido molestias gástricas e incluso entero-colitis por deglución continua de la secreción. Lo más común al acudir el paciente a nosotros es que haya transcurrido un cierto tiempo desde que se produjo la lesión y se haya establecido una sinusitis crónica con más de un episodio de agudización con los síntomas típicos de molestias selectivas en mejilla, fundamentalmente en la salida del infraorbitario, sen-

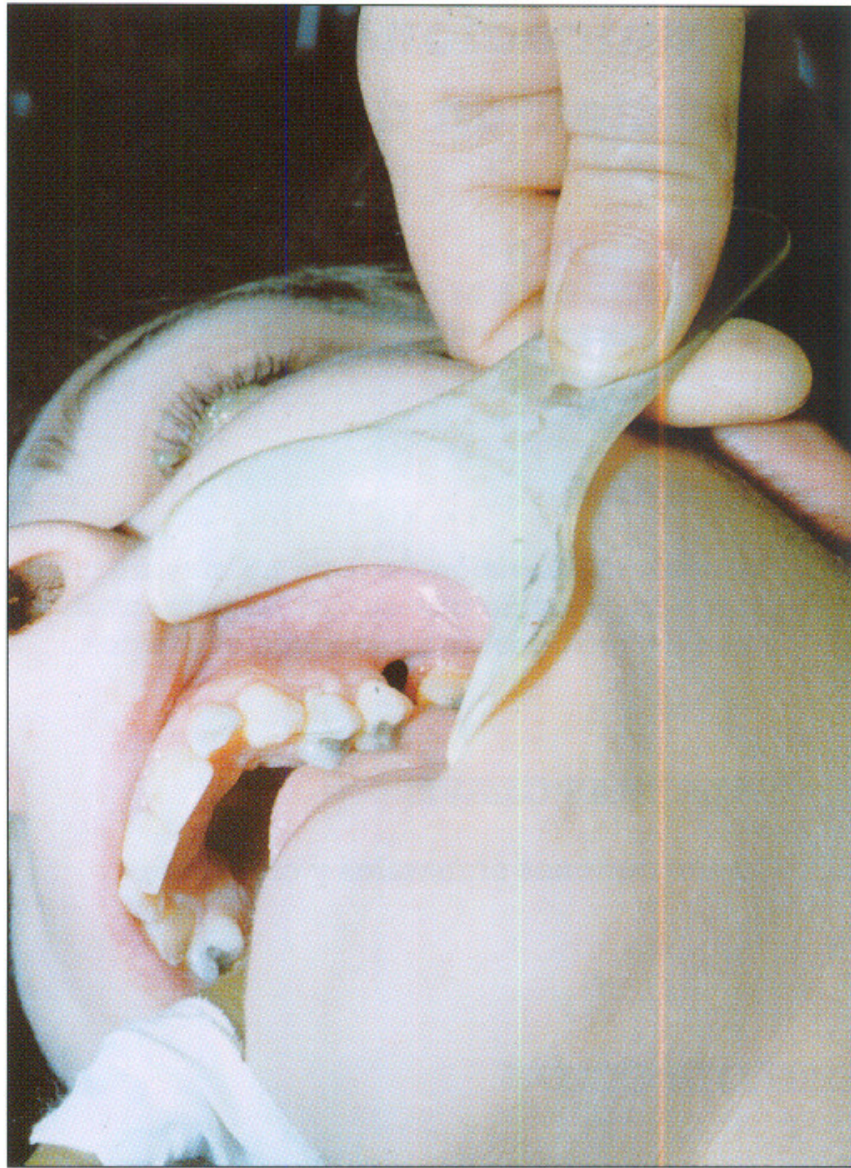

Fig.3

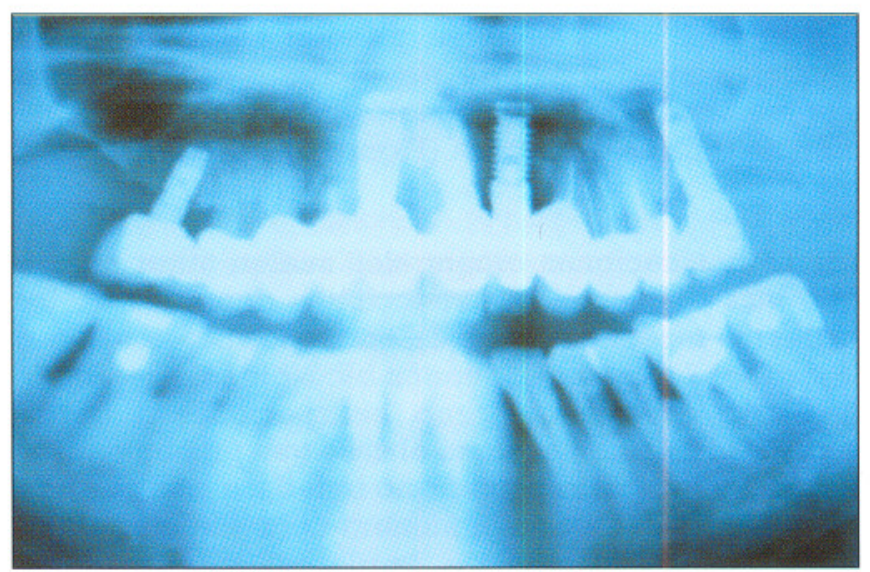

Fig. 4

sación de mal olor, resonancia vocal y en ocasiones, obstrucción nasal de ese lado.

También puede ocurrir, si la fístula es grande, que no haya sintomatología sinusal, debido al buen drenaje del seno.

La localización de las fístulas de origen fisurario suele 


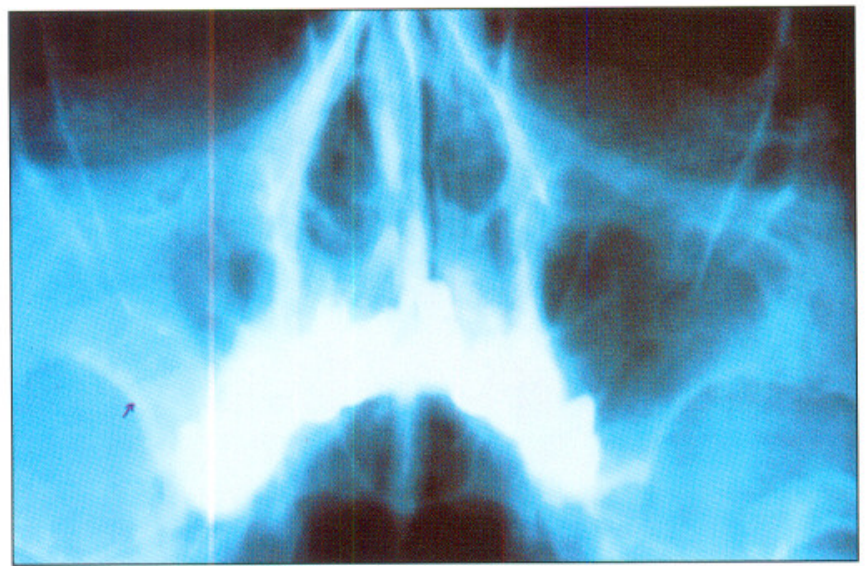

Fig. 5

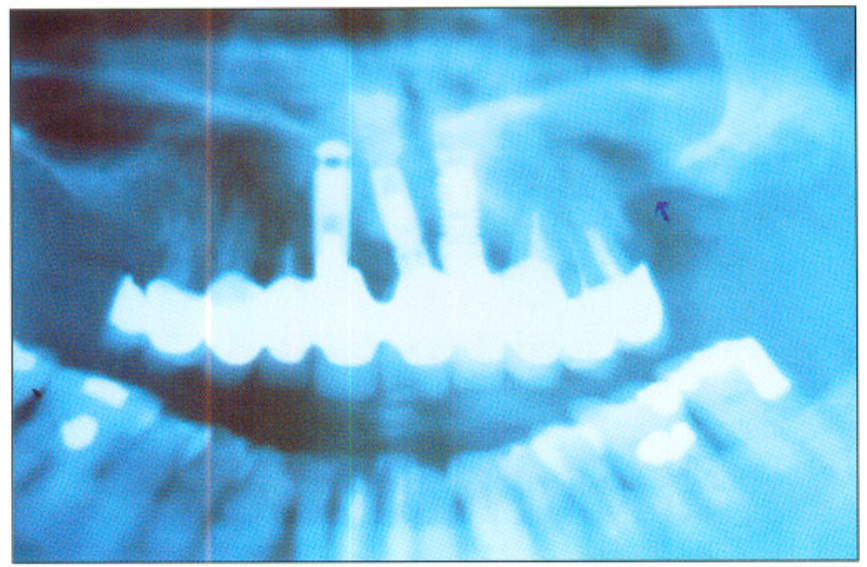

Fig. 6

ser relativamente fácil en una exploración ocular. No ocurre igual en las de otro origen en general (post extracción, traumáticas....) por lo que se aconseja su exploración mediante gutapercha o sonda lacrimal, que nos conducirá a una cavidad amplia confirmándonos el diagnóstico de sospecha. Con su correspondiente estudio radiológico o TAC, podremos ver la ocupación sinusal (Figura 5) y en muchos casos, el trayecto fistuloso (Figura 6).

El tratamiento de estas lesiones tiene como objetivo:

$1^{\circ}$ Prevenir el escape de fluídos

$2^{\circ}$ Impedir la entrada de cualquier contenido bucal al interior nasal o del seno

$3^{\circ}$ Proteger el seno y nariz de las bacterias orales

$4^{\circ}$ En ocasiones, corregir la rinolalia abierta

y dependerá de si las fístulas se hallan o no complicadas con la existencia de una sinusitis.

El tratamiento de las fístulas recientes, pequeñas y sin complicación sinusal de origen traumático postextracción... etc. Si se hace en el momento un simple

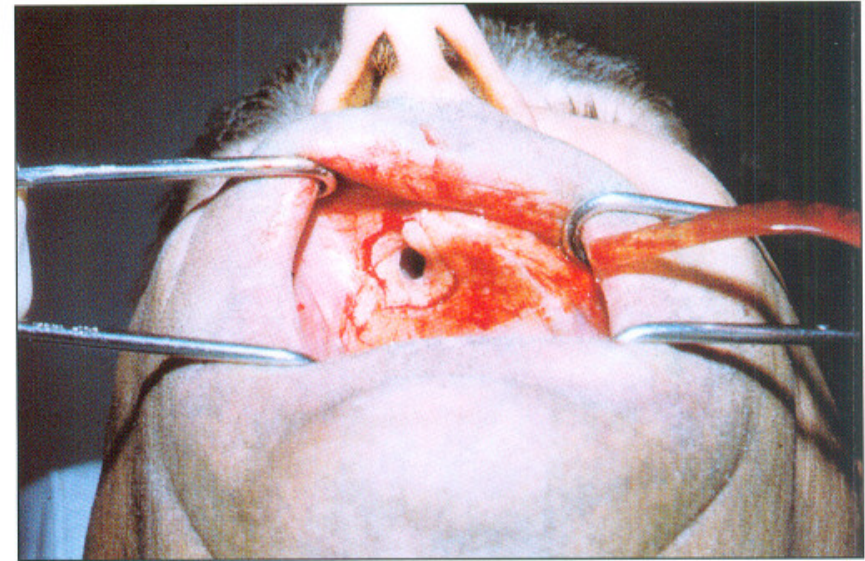

Fig. 7

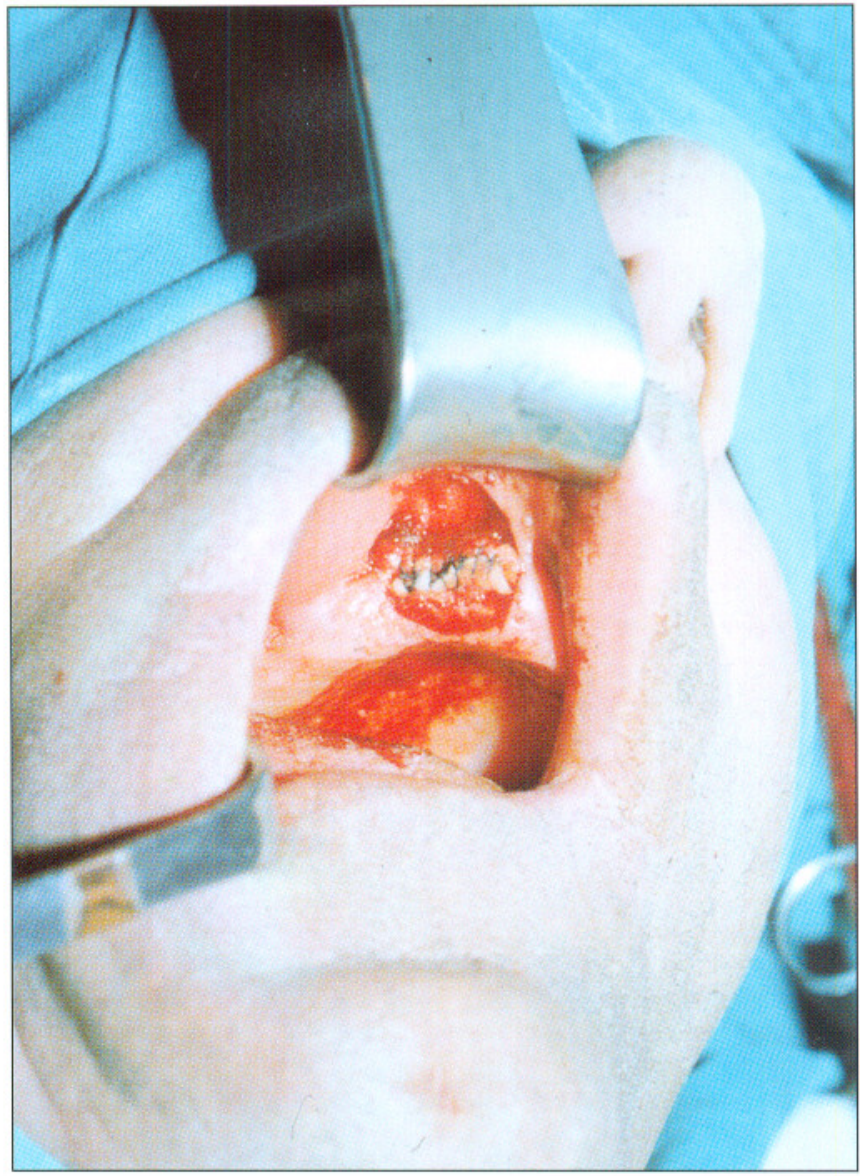

Fig. 8

taponamiento con esponja de fibrina y unos puntos de aproximación de los bordes cruentos suele resolver muchos casos. No debe hacerse nunca un solo colgajo para su cierre y menos, si existe la menor complicación infecciosa porque cosecharemos muchos fracasos por recidiva.

Nosotros tratamos las fístulas mediante dos colgajos 


\section{AVANCES}

Volumen 14 - No 3 - Octubre 2002

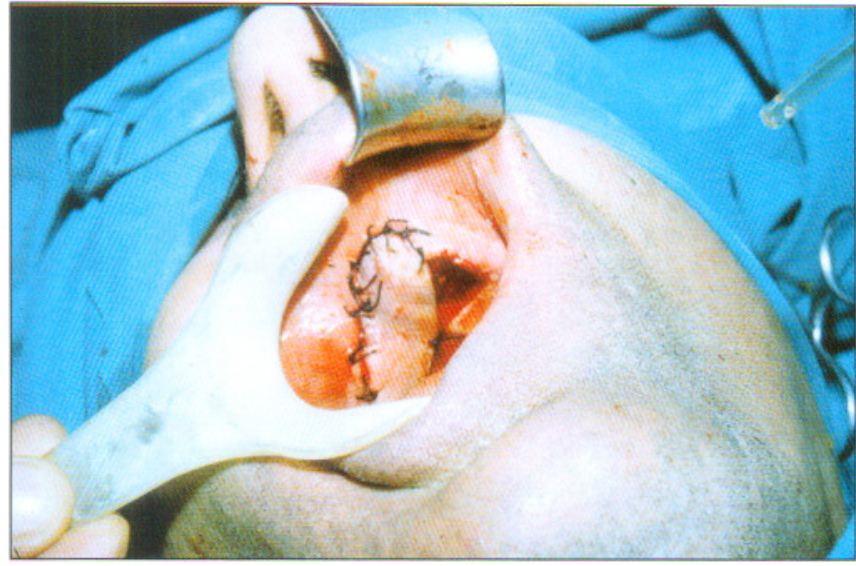

Fig. 9

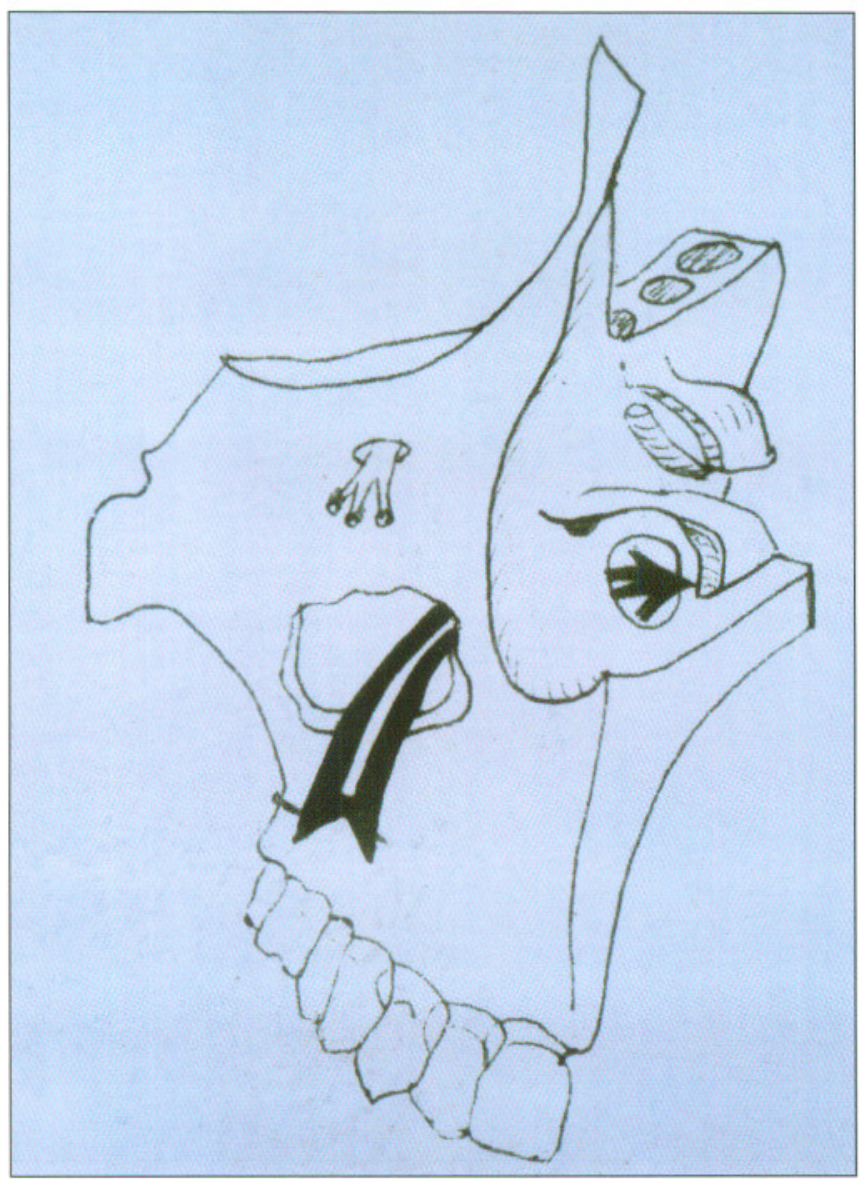

Fig. 10

marginal o interno, seguido de otro por deslizamiento o superficial que cubre al primero.

El colgajo marginal se talla efectuando una incisión que circunscriba la fístula a una distancia de la misma proporcional a su tamaño y que permita afrontar sus bordes (Figura 7). Posteriormente con un periostoto-

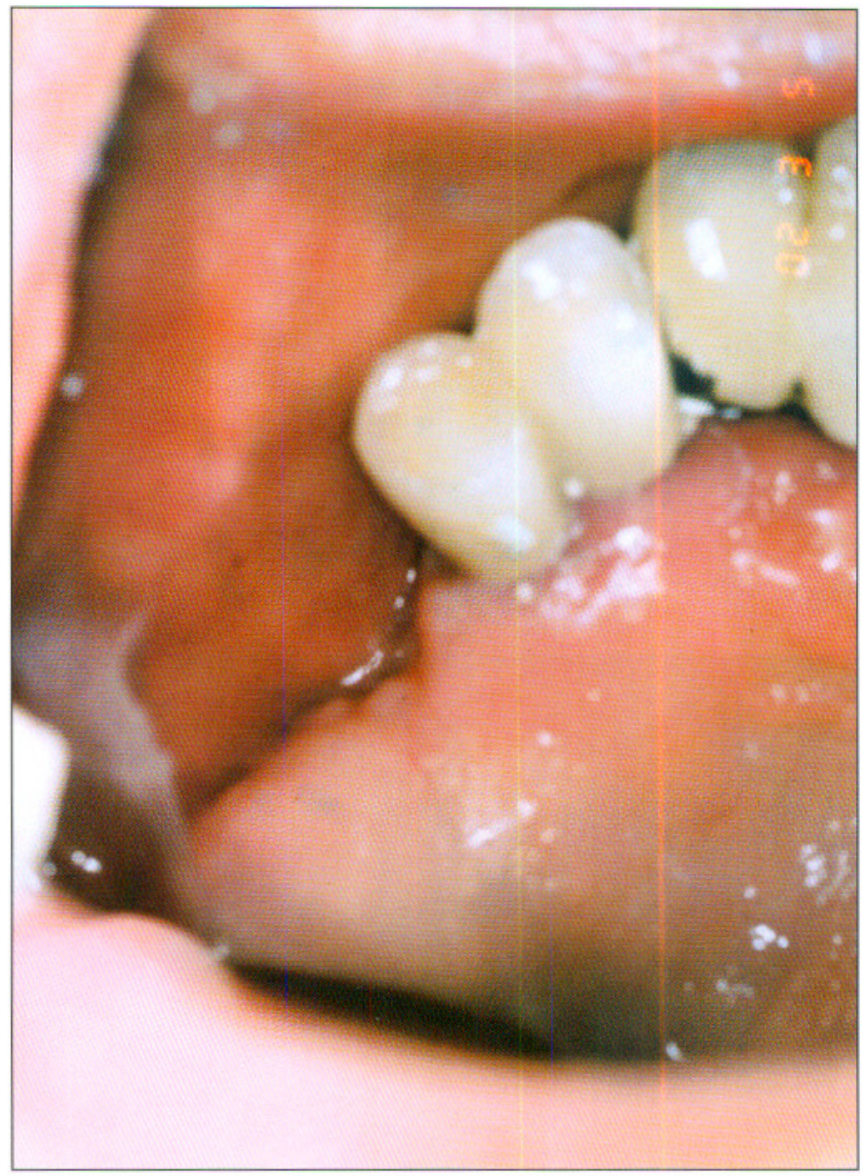

Fig. 11

mo pequeño se desprende el colgajo de su inserción ósea, con cuidado de no lastimarlo, suturándolo a continuación con seda de 3 ó 4 ceros, con puntos invertidos (Figura 8).

El colgajo superficial puede tallarse de tres modos distintos: Un colgajo por deslizamiento bucal, un colgajo de rotación bucal o un colgajo de rotación palatino (Figura 9).

En este tipo de colgajos hay que tener en cuenta en los bucales no afectar la coruncula de la salida del conducto de Stenon, y en los colgajos palatinos no lesionar los vasos de igual nombre.

También existe una técnica en tres planos, mas ideada para las fístulas fisurarias del paladar duro que interpone entre los dos planos ya descritos un injerto de hueso o cartílago autólogo.

Igualmente se ha utilizado en grandes defectos los colgajos de lengua.

El tratamiento de cierre de la comunicación sinusal complicada con sinusitis, se realizará de la forma des- 
crita, complementándola, para que la intervención curse con éxito, con ampliación en sentido anteroposterior de la incisión del colgajo bucal que nos permita el acceso al seno maxilar siguiendo la técnica Caldwell-Luc, para eliminar toda la mucosa sinusal.

Hay que proporcionar un eficaz drenaje del seno mediante una contraabertura nasal (Figura 10). Esta se realizará perforando la pared nasal del seno por debajo del cornete inferior a nivel de la base del meato inferior, con el fin de evitar la lesión del orificio inferior del conducto lacrimonasal que desemboca en la cúspide del meato inferior. Por esta contraabertura, se introduce vía nasal un tubo que nos sirva de drenaje del seno y de aporte de medicación, si lo consideramos pertinente.

\section{CONCLUSIÓN}

Como indicábamos en la introducción, se trata de una patología no muy numerosa de fácil diagnóstico y con una terapéutica bien reglada, pero de difícil ejecución por la falta de espacio, más difícil, cuando se presentan tras la pared o desfiladero dentario que dificulta enormemente la ejecución del primer colgajo mucoperióstico y su sutura invertida, tanto más, cuanto más posterior sea. Por último, indicar nuestro temor de un futuro aumento de fístulas de origen implantario, por ser la $2^{a}$ de este tipo que tratamos en poco tiempo (Figura 11).

\section{SUIMIMARY}

We revise this not very frequent pathology, resulting from the last case of implant origin that was presented to us, observing the most frequent origins as well as existinf treatment methods.

\section{KEY WORDS}

Oronasal and oroantral communication.

\section{BIBLIOGRAFÍA}

1. Gil Tutor E. Quiste odontogénico de seno maxilar izquierdo y fistula orosinusal. An Otorrinolaringol Ibero Anm. 1999; 26: 181-8.

2. Guzel MZ, Altintas F. Repair of large, anterior palatal fistulas using thin tongue flaps: long term follow-up of 10 patients. Ann Plast Surg. 2000; 45: 109-14.

3. Hirata Y, Kino K, Nagaoka S, Miyamoto R, Yoshimasu H, Amagasa T, Kokubyo Gakkai Zasshi. A clinical investigacion of oro-maxillary sinus-perforation due to tooth extraction. The Journal of the Stomatological Society, Japan. 2001; 68: 249-53.

4. Honnebier MB, Johnson DS, Parsa AA, Dorian A, Parsa FD. Closure of palatal fistula with a local mucoperiosteal flap lined with buccal mucosal graft. Cleft Palate Craniofac J. 2000; 37: 127-9.

5. Kraut RA , Smith RV. Team approach for closure of oroantral and oronasal fistulae. Atlas Oral-Maxillofac Surg Clin North Am. 2000; 8: 55-75.

6. Kuran I, Sadikoglu B, Turan T, Hacikerim S, Bas L. The sandwich technique for closure of a palatal fistula. Ann Plast Surg. 2000; 45: 434-7.

7. Lancaster J, Belloso A, Wilson CA, Mc Cormick M. Rare caso of naso-oral fistula with extensive osteocartilaginous necrosis secondary to cocaine abuse: review of otorhinolaryngological presentations in cocaine addicts. J Laryngol Otol. 2000; 114: 630-3.

8. Murrell Gl, Requena R, Karakla DW. Oronasal fistula repair with three layers. Plast Reconstr Surg. 2001; 107: 143-7.

9. Piattelli A, Scarano A, Balleri P, Favero GA. Clinical and histologic evaluation of an active "implant periapical lesion": a case report. Int J Oral Maxillofac Implants. 1998; 13: 713-6.

10. Von Ars DP, Cash AC. Spontaneous palatal fenestration: review of the literature and report of a case. Br J Oral Maxillofac Surg. 2000; 38: 235-7.

\section{CORRESPONDENCIA}

Cirugía Oral e Implantes S.L.

Dr. David Risueño Gómez

C/ Alcalá, $1991^{\circ}$

28028 Madrid 